\title{
Creating a National Digital Learning Environment for Enhancing University Teachers' Pedagogical Expertise - The Case UNIPS
}

\author{
Mari Murtonen' \\ Tampere University \& University of Turku, Finland \\ https://orcid.org/0000-0003-2381-5731 \\ Samuli Laato, Emilia Lipponen, Heidi Salmento \& Henna Vilppu \\ University of Turku, Finland \\ Merja Maikkola \& Paula Vaskuri \\ University of Oulu, Finland \\ Martti Mäkinen \\ Hanken School of Economics, Finland \\ Johanna Naukkarinen \& Terhi Virkki-Hatakka \\ Lappeenranta University of Technology, Finland \\ Eila Pajarre \& Sara Selänne \\ Tampere University, Finland \\ Terhi Skaniakos \\ University of Jyväskylä, Finland
}

\begin{abstract}
This article analyses the design, implementation, and evaluation of a nation-wide project to create a common digital solution for university teaching staff's pedagogical training in Finland. During three years, eight universities collaborated in developing an online learning platform called UNIPS, the University Pedagogical Support system. The areas to develop were A) a learning platform based on technical design principles, B) pedagogical principles, and C) broadening the scope of offered studies. The results have been promising. With a carefully planned timetable, all participating universities were able to produce, test, and offer UNIPS modules in collaboration with other universities on the area of their expertise. This paper presents the design process and looks at both developers' experiences on how they perceived the process and the UNIPS platform
\end{abstract}

\footnotetext{
${ }^{1}$ Corresponding author: Mari Murtonen, mari.murtonen@tuni.fi
} 
as its result, and students' experiences about studying in the UNIPS platform.

Keywords: university teaching; higher education; pedagogical training; pedagogical support; digital solution

\section{Introduction}

University teachers have traditionally been a group who do not receive any pedagogical training before they begin to work as teachers, and even later in their teaching career, their pedagogical training is mostly voluntary (Murtonen \& Vilppu, under review). In recent years, the demand for staff development courses and lifelong learning opportunities has increased (Hyland, 2019), and universities have been constantly evaluated and accredited for their success in teaching. University teachers are required to be aware of the latest pedagogical changes in their field in order to be able to provide high quality teaching.

The reasons for the lack of pedagogical training and teaching staff's weak pedagogical education in universities are numerous. The Humboldtian tradition of universities in many countries relies on the high-quality content knowledge and collaboration in research groups that is assumed to ensure the high-quality teaching (Simons, 2006; Simons \& Elen, 2007). When pedagogical training is offered, the staff may not be interested in participating because of the traditional thinking that pedagogical skills are not needed. Those who might be interested in participating may not be able to attend fixed training sessions due to busy working schedules. Employee training courses on pedagogy have been expensive for universities to organize and staff for organizing them has been scarce, and since only the most experienced applicants have been selected, all who wanted to participate may not have received a study place (Vilppu, Södervik, Postareff, \& Murtonen, 2019). This leaves, again, the beginning teachers uneducated. If a selection criterion to training has been working as a teacher at the university, doctoral students without teaching duties have usually been left out, even if they may have been interested in participating.

Many Finnish universities are struggling with the above-mentioned issues. Another severe problem is that the pedagogical training has been offered in many universities only in Finnish, leaving international staff and doctoral students out. For these reasons, there was demand for a modern learning solution that would enable busy staff members, all doctoral students, and nonnative Finnish speakers to participate in university pedagogical courses, preferably with a lower cost than in face-to-face training. The goal was also to develop the content of the training in order to meet the goals set in the strategies of the Finnish universities.

To meet the demand, an idea of a common digital learning platform was born among the university pedagogical developers of the Peda-forum, a network of university-level actors and teachers in Finland. The University of Turku was the first one to develop a digital learning platform prototype named UTUPS (University of Turku Pedagogical Support) that was tested and consolidated in use during 2015-2017. Since struggling to provide pedagogical training for 
university staff was a common problem in middle-sized and small universities, the success of the UTUPS sparked the interest of other Finnish universities. A key funding application was produced in collaboration and the Finnish Ministry of Education and Culture decided to fund the UNIPS project, a joint effort of eight Finnish universities (out of a total of 13 universities), coordinated by the University of Turku, from the beginning of 2017 until the end of 2019 (see Figure 1).
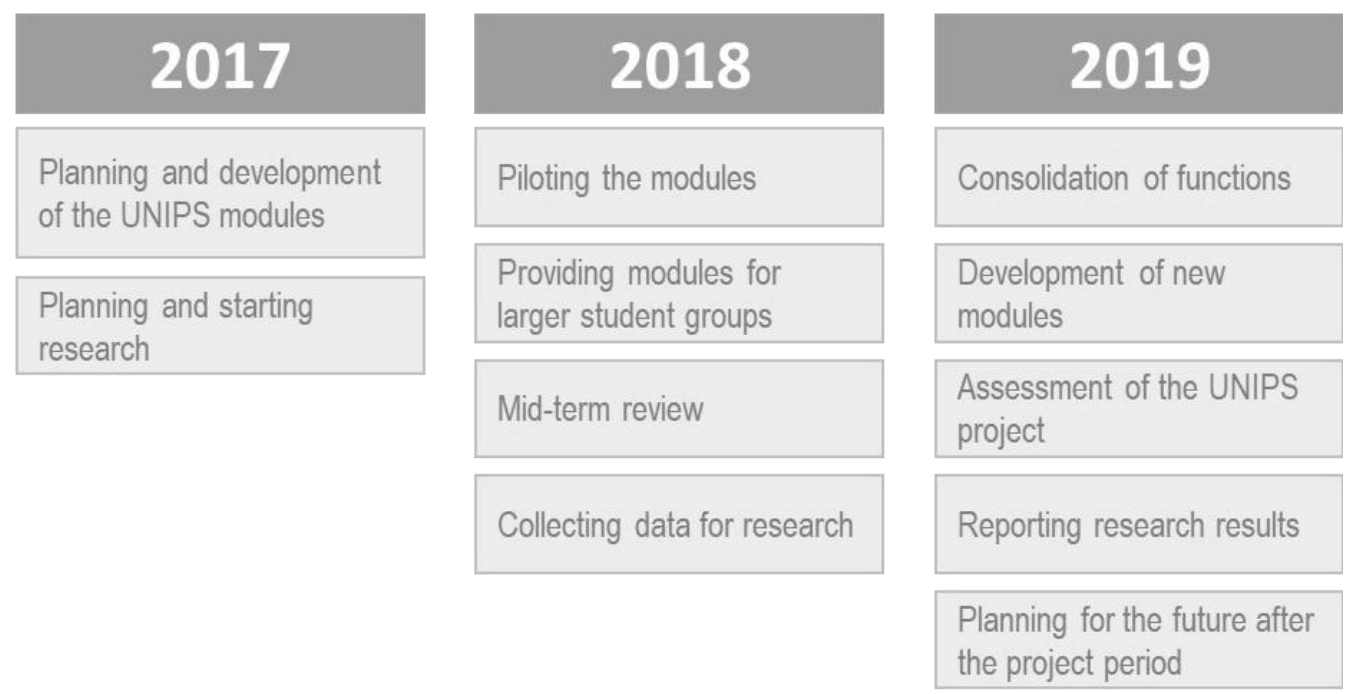

Figure 1: Implementation plan of the UNIPS project during years 2017-2019

The aim of the project was to produce an environment that builds on the findings of the learning sciences, i.e. to provide a best possible environment to foster and support participants' learning, and that uses the most inspiring digital solutions available. This paper describes the design and implementation of the UNIPS platform and analyses the experiences of both the developers of the platform and students who studied in the platform. The analysis is done both at the levels of pedagogical and technical solutions. The goal is to describe the most successful solutions for developing and executing such a digital environment, and how to avoid possible pitfalls. In addition, some visions for the future will be set, especially concerning the continuity of this type of an environment after the funding period.

\section{The theoretical standing points and practical requirements for designing the UNIPS platform}

The focus in designing the UNIPS platform was to produce high-quality university pedagogical material online and provide an easy access to that material. Thus, the goal was to enable staff members' self-studying on various higher education pedagogy topics whenever they would need information to support their teaching (cf. Laato, Salmento, \& Murtonen, 2018). A further goal was also to incorporate material for the guided study model, which would utilize online teamwork for collaborative improvement of pedagogical skills and allow students to earn study credits in the guidance of a teacher. These objectives posed various challenges to feasible technical and pedagogical 
solutions and affected the way content was chosen and created. Due to the complexity of online courses, best practices and lessons from previous studies needed to be taken into account already in the design phase. The solution also needs to be constantly evaluated through theory and practice.

This chapter will describe the agreed design principles, the actual implementation solutions of the UNIPS platform from the viewpoints of technical, pedagogical, and scope related requirements and possibilities, and the theoretical standing points of the design principles and the implementation. The most important goals and solutions are summarized in Table 1.

Table 1: The requirements and initial solutions of the UNIPS platform

\begin{tabular}{|c|c|c|}
\hline Goal & Specific requirement & Implementation solution \\
\hline \multicolumn{3}{|c|}{ A. TECHICAL PLATFORM DESIGN PRINCIPLES } \\
\hline $\begin{array}{l}\text { A1. Flexibility \& } \\
\text { easy accessibility } \\
\text { for students }\end{array}$ & $\begin{array}{l}\text { Materials available at all } \\
\text { times, everywhere, for } \\
\text { everyone }\end{array}$ & $\begin{array}{l}\text { Provide materials online; no } \\
\text { registration or password }\end{array}$ \\
\hline $\begin{array}{l}\text { A2. Ensure the use } \\
\text { of the platform in } \\
\text { universities }\end{array}$ & $\begin{array}{l}\text { Make the solution } \\
\text { practical, easy and low- } \\
\text { cost to maintain }\end{array}$ & $\begin{array}{l}\text { Use free software technologies - in } \\
\text { practice: WordPress CMS and } \\
\text { Moodle }\end{array}$ \\
\hline $\begin{array}{l}\text { A3. Ensure the use } \\
\text { of the materials in } \\
\text { universities }\end{array}$ & $\begin{array}{l}\text { Make materials relevant } \\
\text { and fit the current } \\
\text { ecosystem of university } \\
\text { pedagogical teaching }\end{array}$ & $\begin{array}{l}\text { Modular structure enables: } \\
\text { - Use within various teaching } \\
\text { methods (e.g. flipped learning, } \\
\text { traditional teaching, self-study, etc.) } \\
\text { - Studying modules as individual } \\
\text { study units or including contents } \\
\text { into other courses } \\
\text { - Use of micro credentials or badges }\end{array}$ \\
\hline \multicolumn{3}{|c|}{ B. PEDAGOGICAL PRINCIPLES } \\
\hline $\begin{array}{l}\text { B1. Support } \\
\text { learning and } \\
\text { avoid dropping } \\
\text { out by good } \\
\text { usability and } \\
\text { attractiveness }\end{array}$ & $\begin{array}{l}\text { Minimize students' } \\
\text { cognitive load and make } \\
\text { studying attractive by } \\
\text { gamifying contents and } \\
\text { making elements } \\
\text { interactive }\end{array}$ & $\begin{array}{l}\text { - Include only necessary information } \\
\text { - Short snippets of information and } \\
\text { small packets of learning } \\
\text { - Basically same design and structure } \\
\text { in every content module } \\
\text { - Motivating, interactive materials, } \\
\text { e.g. activating tasks, quizzes, tests } \\
\text { and short videos }\end{array}$ \\
\hline $\begin{array}{l}\text { B2. Enhance } \\
\text { collaborative } \\
\text { knowledge } \\
\text { building }\end{array}$ & $\begin{array}{l}\text { Include social features \& } \\
\text { collaborative learning }\end{array}$ & $\begin{array}{l}\text { Use external technologies to facilitate } \\
\text { group discussions and collaborative } \\
\text { tasks with shared goals }\end{array}$ \\
\hline $\begin{array}{l}\text { B3. Enhance } \\
\text { reflection skills } \\
\text { and conceptual } \\
\text { change }\end{array}$ & $\begin{array}{l}\text { Include possibilities for } \\
\text { metacognitive processes } \\
\text { and challenging one's } \\
\text { own knowledge }\end{array}$ & $\begin{array}{l}\text { Individual and collaborative tasks to } \\
\text { create conceptual conflict and need } \\
\text { for reflection }\end{array}$ \\
\hline \multicolumn{3}{|c|}{ C. BROADENING SCOPE } \\
\hline $\begin{array}{l}\text { C1. Broadening } \\
\text { participant group }\end{array}$ & $\begin{array}{l}\text { Provide teaching for new } \\
\text { teachers and PhD } \\
\text { students }\end{array}$ & $\begin{array}{l}\text { Scalable online courses to control } \\
\text { organizing costs }\end{array}$ \\
\hline
\end{tabular}




\begin{tabular}{lll}
\hline $\begin{array}{l}\text { C2. Broadening } \\
\text { language selection }\end{array}$ & $\begin{array}{l}\text { Teaching available in } \\
\text { English }\end{array}$ & $\begin{array}{l}\text { Create all materials in English or } \\
\text { provide translations }\end{array}$ \\
\hline $\begin{array}{l}\text { C3. Broadening } \\
\text { content selection } \\
\text { and quality of } \\
\text { materials }\end{array}$ & $\begin{array}{l}\text { Offer wider selection of } \\
\text { high-quality courses }\end{array}$ & $\begin{array}{l}\text { Co-plan and co-produce the open } \\
\text { modules for national purposes }\end{array}$ \\
\hline \hline
\end{tabular}

\subsection{Technical platform design principles}

Since the goal was to create a flexible digital environment, the first task in designing the learning solution was to select suitable tools for implementing the pedagogical ideas. The first question was whether the environment should be open or closed. Since the funder, The Ministry of Education and Culture, requires open access solutions, and also because the aim was to create easily accessible materials, an open solution was selected. The internet provides unique opportunities for higher education. Massive open online courses (MOOCs), meaning courses that are open to all who are willing to study, as well as learning management systems (LMSs), i.e. software applications for managing educational courses, have emerged, providing educational resources for students regardless of their physical location. The development costs of quality online educational materials can be high; however, those are fixed one-time costs, and, as the maintenance and redistribution of the created content is cheap compared to contact teaching, this allows the universities to use the solution for a long time. Since the universities in Finland operate mainly on public funding, the costs for each university to develop and maintain the environment needed to be low. Thus, mainly such software were selected that already were used by all universities or that were free or low in cost. The domain name unips.fi was reserved for the platform and a web hotel was rented to host the site. The WordPress content management system (CMS) was then installed on the server, on top of which the main UNIPS website and all pedagogical materials were deployed. According to design science research approaches, such as the Hevner design science (Hevner, 2007), information to the artifact must be obtained both from a knowledge base (scientific articles) as well as the environment (UTUPS prototype). The UNIPS artifact went through several iterations where both the website visuals and order of materials were improved upon. In autumn 2017, three pilot modules, each worth one credit point, were offered to staff members and doctoral students at the University of Turku. At the same time the website was made accessible with no password to make the materials available for everyone. Since 2017, all UNIPS content has been licensed under the Creative Commons Attribution-ShareAlike (CC-BY-SA) license. The design of the website and the technical background solution was designed together with participating universities. The coordinating university, the University of Turku, was the administrator in executing the solution. However, each university was responsible for developing their own materials on the module website.

In order to offer easily measurable and comparable short courses among eight universities, it was decided to organize pedagogical materials into small packets of 1 ECTS credit (European Credit Transfer and Accumulation System). The materials were designed to the UNIPS website in a manner that allows one module to fit entirely on a single webpage. The materials can be used in self- 
study, guided study with credit points, and as parts of pre-existing teaching, for example, via utilizing flipped learning strategies, i.e. using the material as a prematerial for a face-to-face meeting. The modular structure of the UNIPS learning solution enables learners to quickly find materials related to specific topics of their interest. The materials are available on the website at all times without login or registration requirements. Furthermore, available modules are accessible via two clicks after arriving on the front page. The modular structure and small packages also allow universities to update the content easily and to add new modules to the platform.

Participating universities offering the modules have utilized additional technical solutions to support their UNIPS courses. For example, LMSs such as Moodle have been used for accepting registrations and organizing the courses. Another connected software that has been used with UNIPS is Google Docs for collaborative writing. Also, Webropol has been used for purposes of module enrolment and to collect research data and student feedback. The aim of making the UNIPS platform easy to use in connection to other software that universities are currently using is hoped to foster the use of UNIPS.

\subsection{Pedagogical principles of the UNIPS-platform}

The UNIPS platform and the contents were designed to support both individual self-study and studying in a more teacher-led guided study format. According to Picciano (2017), teacher-led fully online courses have the advantage of being able to offer more guidance and interaction for the students; however, one of the disadvantages is that the courses cannot be fully automated and can only be organized at times when a teacher is available. The UNIPS modules in the current format are not automated and they require teacher guidance at certain points to allow the student to move forward in the module. However, since the courses are short, the teacher's role is mostly administrative in guiding students to fulfil the certain tasks at certain points, and not so much on guiding the learning process itself. As most of the UNIPS modules are for beginners, the teacher's task was planned to be mainly an observer who takes care that no misconceptions were formed and no irrelevant discussions emerged.

Massive Open Online Courses (MOOCs) can typically have dropout rates as high as 90\% with Small Private Online Courses (SPOCs) dropout rates being a bit lower (Eriksson, Adawi, \& Stöhr, 2017; Laato, Lipponen, Salmento, Vilppu, \& Murtonen, 2019). The biggest spike in dropouts is almost always in the beginning of the online course and it approaches zero as the course progresses. The reasons why students quit online course participation are numerous, and hence, also strategies used to increase student retention are numerous (Khalil \& Ebner, 2014). Eriksson et al. (2017) found four main reasons why students dropout from online courses: (1) learners' perception of the course content, (2) learners' perception of the course design, (3) learners' social situation and characteristics, and (4) learners' ability to find and manage time effectively.

In order to avoid solutions that increase the dropout rates, we aimed at selecting and applying pedagogical features that support learners' learning actions but do 
not burden their capacity. A theoretical framework for this task was the Cognitive Load Theory (CLT), which is built on taking into account humans' cognitive architecture where working memory and cognitive processing capability are limited (Paas, Tuovinen, Tabbers, \& Van Gerven, 2010). According to CLT, instructional methods using too much of the limited cognitive capacity can result in cognitive overload, which leads to a situation where the learner cannot learn. Cognitive overload has been identified as a reason for students to yield participation in online courses by several studies (Huang et al., 2017; TylerSmith, 2006; Oakley, Poole, \& Nestor, 2016). Additionally, minimizing cognitive load in the instructional design has been shown to produce better learning results (Mayer, Moreno, Boire, \& Vagge, 1999). It is thus no wonder that CLT has been applied previously in the design of online learning environments and tools to minimize cognitive load of learners and enhance positive outcomes (Feinberg \& Murphy, 2000; Heo \& Chow, 2005; Tracy \& Albers, 2006). The cognitive load aspect was taken into account in both technical and pedagogical solutions of UNIPS. The pedagogical principles to reduce cognitive load were, for example, giving clear learning outcome goals, organizing materials in small packets that contain only one central idea or message, and offering interesting ways to study with repeating the same module structure in every module.

A particularly important and challenging aspect of online learning is how to incorporate social features in the learning platform in a way that would benefit students. Social presence is related to students' satisfaction and perceived learning (Richardson, Maeda, Lv, \& Caskurlu, 2017). A systematic literature review on the dropout rates in MOOCs found students' feeling of isolation to be one of the biggest reasons for course withdrawal (Khalil \& Ebner, 2014). Thus, increasing the feeling of social presence and scaffolding meaningful social interactions in the UNIPS modules was an important aspect in the development process. Social interaction in online learning can be divided into two categories: synchronous and asynchronous (Hrastinski, 2008). Synchronous activities require students to be present at the same time. These activities have the advantage of rapid feedback and provide learners more real life-like interaction. On the other hand, asynchronous activities enjoy the benefit of not requiring attendance at a fixed time, and can thus be more suitable for employee training courses where students are busy with other activities besides studying. Examples of asynchronous solutions are forum type of discussion and anchored environments. There are a lot of tools available; however, finding a tool that would foster "deep and authentic" discussions instead of superficial commenting to fill the requirements to pass the course can be challenging. Some social media channels might enable this kind of discussions; nevertheless, they can be problematic for online learning as the prominent ones are owned by private companies and require external registration.

In UNIPS, social features were fostered in two ways: in the beginning of the group work period, the participants introduced themselves to the other group members, which aimed to reduce the feeling of isolation. Secondly, the participants had asynchronous discussion on the basis of their own essays, which was hoped to evoke discussion since they all had written text on the same 
topic. The social features are also crucial since they enhance collaborative knowledge building processes aiming at the development of pedagogical expertise (e.g. Hakkarainen, Palonen, Paavola, \& Lehtinen, 2004). As collaborative learning and social presence have been shown to provide multiple benefits for online learners (Combéfis, Bibal, \& Van Roy, 2014), collaborative features were included in the guided study of the modules. Computers can support collaborative learning in several ways. The primary form of support is to provide a medium for communication; however, computer-supported learning environments can also provide various other forms of scaffolding (Stahl, Koschmann, \& Suthers, 2014). The basic idea of the UNIPS platform is to bring together participants from different disciplines and universities. Providing them an opportunity to exchange ideas and share views is likely to support their meaning making regarding university pedagogy even without complex computational feedback and interaction mechanisms and thus also to support collaborative learning. The same process also helps to develop teachers' reflective metacognitive skills as well as to foster conceptual development and even change by creating possibilities for cognitive conflicts in knowledge building situations (e.g. Mikkilä-Erdmann, Ahopelto, Virtanen, Kääpä, \& Olkinuora, 2012).

\subsection{Broadening the scope of pedagogical trainings}

One of the most important goals of the UNIPS project was to help universities to offer pedagogical training for a wider selection of teachers and prospective teachers than before. Respecting teachers' varying situations, e.g. rushed working hours, difficulties to participate in contact teaching, and language limitations, the UNIPS project aimed at offering universities a solution that could be used in a very flexible way. By utilizing the current ideas of micro credentials and continuous learning, the UNIPS platform allows participants to start with small studying packages and continue their learning to the direction they feel important.

After designing the above-mentioned technical and pedagogical principles of UNIPS, the themes and topics of the modules were planned together with the same project group to fulfil the needs of various university teachers and to increase the quality of offered trainings. The module topics range from basic university pedagogical contents, such as "Becoming a teacher" and "How to plan my teaching" to more specific themes, such as pedagogics in digital learning, standards and guidelines in teaching, competency-based curriculum, and working life collaboration. The modules were worked on in small teams of 1 to 3 universities based on their interests and special experience, skills, and knowledge of the theme. The teams were self-organized and the created modules were evaluated in the whole group of eight universities before publishing them on the UNIPS website.

The module contents consist of, for example, research articles, educational videos, interactive exercises, and various other tasks. In the case of self-study, some assignments for helping students to review and test themselves were sometimes included. In the case of guided study, different kinds of group 
activities that were planned to strengthen interaction during the courses could be used. Examples of these activities are, for example, face-to-face synchronous discussions, asynchronous discussions held in an online learning environment or even in social media, peer feedback, co-writing or co-creating, and any activities that support learning in small groups moderated by an instructor.

The personnel responsible for the development of the modules were also given the responsibility to design how the materials are supposed to be used in the guided study and produce a teacher's guide for helping utilize the modules in different universities. Most of the UNIPS modules that are used as guided study modules are organized as teacher-led fully online courses that could use additional supporting technologies such as a learning management system (LMS) and collaborative learning tools. The contact between students and teacher is important in these types of environments. Being present at the course site, creating collaboration between students and supporting individual tasks, and giving timely feedback for students participating on a course are important (e.g. Bailey \& Card, 2009; Boettcher \& Conrad 2016).

After building the content, the modules were tested at partner universities with real students. Each of the modules were piloted at least once, some several times. Based on the experiences, the module contents and the teacher's guides were developed further. The final UNIPS website module selection is displayed in Figure 2. It was also decided that when one university offers a module, it can accept students also from other participating universities. By this system the students were offered a wider range of modules than by only offering their own university modules.
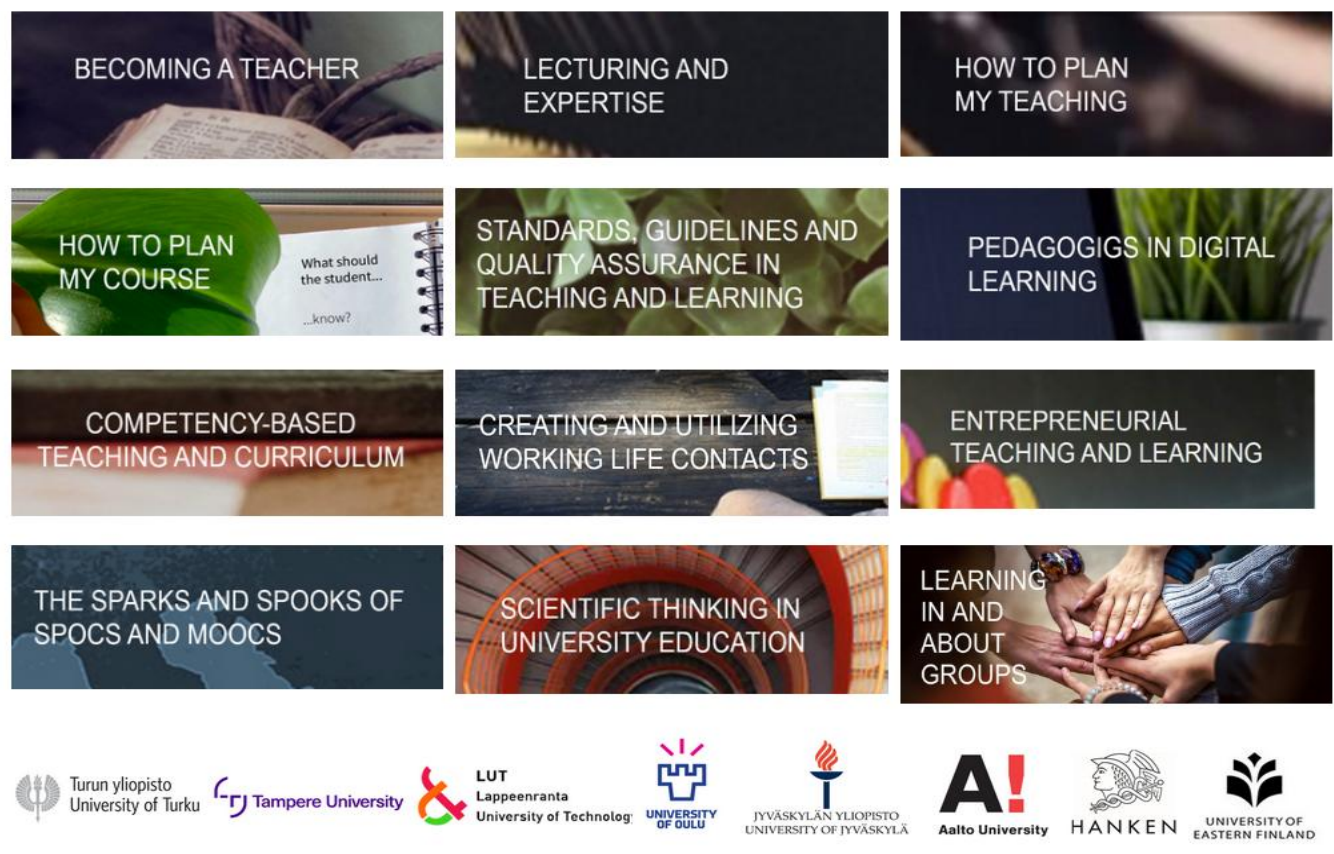

Figure 2: Twelve modules developed during the UNIPS project, available on the https://unips.fi website 


\section{Evaluating the developers' and students' experiences of the UNIPS platform}

In the above the process of planning and deciding the technical and pedagogical principles for the UNIPS platform within the key funding project group of eight universities has been described. In order to study whether the goals were obtained, a study with two groups was conducted: the developers of the UNIPS and the students of UNIPS. The aim was to explore 1) how the developers of UNIPS learning solution have perceived the process and the resulting product, the UNIPS platform, and 2) how UNIPS works from the viewpoint of UNIPS students, i.e. teachers and doctoral candidates who have studied the modules. In addition, some statistics concerning the number of educated staff will be presented.

\subsection{Participants}

The participating developers were the developer groups (consisting of up to five people) of the UNIPS learning solution from eight Finnish universities (University of Turku, University of Jyväskylä, Tampere University, Lappeenranta University of Technology, University of Eastern Finland, University of Oulu, Aalto University and Hanken School of Economics). Since the amount of staff varied during the project, the developers were asked to respond as groups so that one response was received from each university. All universities responded.

The participating students $(N=81)$ responded to a feedback questionnaire after studying some or all of the three generic modules Becoming a teacher, Lecturing and expertise or How to plan my teaching in spring $2019(n=43)$ or autumn 2019 ( $n$ $=38$ ), organized by the coordinating university, the University of Turku. These timings were selected because the year 2019 was the last of the three-year project period and then the modules had already been piloted to ensure their functioning (see Figure 1). The students of the modules represented several disciplines and came from different universities in Finland. Responding to the feedback questionnaire was voluntary and anonymous, and detailed background information, such as university or discipline, were not asked.

\subsection{Data collection and analysis}

In order to find out developers' experiences and the best solutions in planning and executing this type of an educational platform, we created a questionnaire to focus on the most central aspects of this kind of learning solution on the basis of prior literature. The created questionnaire consisted of both open-ended questions and Likert-scale statements concerning developers' experiences and opinions about the technical and pedagogical decisions and implementations in UNIPS. For example, the developers evaluated the realization of the pedagogical goals of UNIPS, such as flexibility of studies and usability of the environment, on a Likert-scale from one to four $(1=$ poorly, $\ldots, 4=$ very well $)$. Experiences of technical solutions and compatibility with other software and platforms were evaluated by open-ended questions. 
Feedback from students who completed UNIPS modules was collected with a feedback questionnaire that was created for the UNIPS purposes, with a focus on user experiences. The data was collected in the end of the project period that was also the time when the modules had been piloted to ensure their working. The students' questionnaire consisted of open-ended questions and Likert-scale statements aiming to explore how the participants have experienced the technical and pedagogical solutions. On a scale form one to five $(1=$ strongly disagree, $\ldots, 5=$ strongly agree), the students evaluated for example the layout and the design of the environment and clearness of the instructions. Open-ended space was provided for improvement ideas and other feedback.

The data of both of the questionnaires was analyzed quantitatively and qualitatively. The Likert-scale ratings are presented with descriptive statistics. The qualitative responses were content analyzed by searching for themes that the respondents brought up. Due to the small amount of respondents, no numerical data about developers' answers is presented.

\section{Results}

Before presenting the results of the questionnaires, we present some statistics about the staff that has been educated through UNIPS during the project period. Based on the amount of modules completed during the whole project, UNIPS has succeeded to increase the amount of pedagogical training in Finland. For example, between 2017-2019, 285 participants have completed 1-3 of the UNIPS modules Becoming a teacher, Lecturing and expertise, and How to plan my teaching organized at the University of Turku. The total number of credits completed by studying these modules during the project is 630, and the number of students (taking 1-3 modules) was almost 300, while normally the number of students taking basic courses during three years would have been around 150. The participation has been active from all the disciplines: 47 of the participants were from the faculty of Humanities, 48 from Science and engineering, 68 from Medicine, 6 from Law, 26 from Social sciences, 24 from Education, 34 from Economics, and 32 from other faculties or units. The participants were staff members $(n=93)$, doctoral students with teaching duties at the university $(n=$ 68 ), and doctoral students without teaching duties at the university $(n=$ 123). When taking into account the modules arranged by UNIPS staff in other partner universities, the amount of study credits is even higher. Thus, the goal of increasing the number of pedagogically educated staff has been reached. Especially the number of doctoral students who do not have teaching duties at a university is high, and they probably would not have had an opportunity to study pedagogy without UNIPS.

\subsection{Developing UNIPS learning solution - the viewpoint of the developers}

Developer groups from all the participating universities $(N=8)$ answered the questionnaire concerning their experiences of the process and the product, the UNIPS learning solution. The developers evaluated the realization of the pedagogical goals of UNIPS overall quite positively (see Figure 3). Factors that received the most positive evaluations were increasing the offering of studies in English, flexibility of studies, self-reflection in learning, and diversifying the 
content of instruction. However, better cooperativeness of learning was wished for. Also, the accessibility and quality of instruction were thought to be not as good as possible.

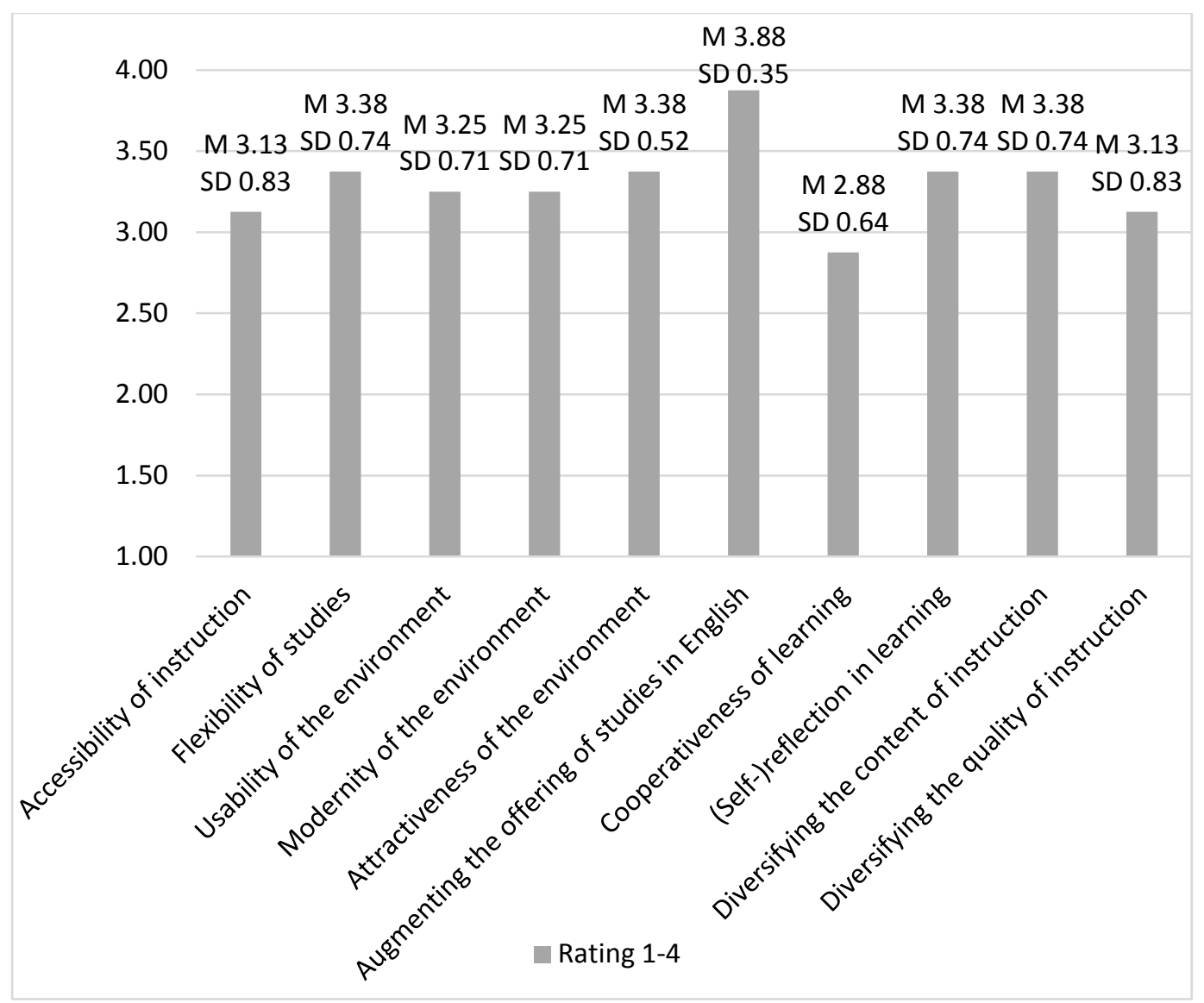

Figure 3: Developer groups' evaluations of the UNIPS learning solution

To gain a deeper insight into developers' views, we also gathered qualitative feedback from them. The developers did not report major problems with the technical solutions of the UNIPS (WordPress, H5P plugin). Most of the developers considered them reliable, easy to use, and good for co-creating web content, but at the same time quite static, restrictive, and non-interactive. The channels of social media proved to be excellent support services for this kind of project aiming to create something new. A considerable amount of time was used in the beginning on negotiating about the suitable online platform. According to the developers, the selected content management system, WordPress, worked well, also with other software, such as Moodle and YouTube. Overall, extensive use of external tools was perceived as challenging for both the facilitator and the learners. A few respondents brought up that it would be most convenient to have it all at the same webpage:

"The best solution would be a learning environment that looks like a home page (like WordPress), but then have a closed area inside the environment where all the assignments would be returned and space for the group work and so on." 
“- - a login and personified LMS would be required to be able to display instructions to students on the website itself."

"- - when you use Moodle it is more convenient for the students to use only Moodle."

The developers considered preparing UNIPS materials together with colleagues outside their own university useful, and even fun. In the beginning there may have been some misunderstandings; however, these were solved by negotiation and cooperation. Linking the journal articles to the open website was problematic because the library links are university-based and require a user identification. Videos were the most popular form of content delivery. The videos were made with iPads and iMovie, Planet eStream and green screen studio, for instance. Making videos was considered an arduous and timeconsuming process by some, and more support from home university was wished for, especially in the beginning of the project. Careful planning and a good script were the most frequent tips given for making video materials. Also, a prompter was considered to be useful in helping the teachers appear natural when recording the videos.

When the developers where asked about surprises or critical incidents in the UNIPS process, some issues were raised concerning communication and cooperation between the participating universities. For example, a shared communication platform (such as Microsoft Teams) could have made working with other universities more dynamic than using one university's Moodle, which functioned merely as a storage for materials and information. In addition, some developer groups worked tightly together whereas others were more loosely organized. Furthermore, unexpected changes in personnel during the project were considered a critical incident that might even jeopardize the whole project, but fortunately, that did not happen in this case. The big number of dropouts was a surprise for one university, although the dropout rates for UNIPS modules have been relatively small compared to other online courses: in UNIPS the dropout rate has been around 55\%, while in some other environments it has sometimes been as high as $90 \%$ (Laato et al., 2019).

All the participating universities had offered the UNIPS modules as 1 ECTS courses. The universities had given either study credits or certificates of participation to the students. In some universities, UNIPS courses could be accredited into doctoral studies or other (pedagogical) studies. However, some universities reported having severe problems with administration, stating that the official study register is too inflexible for small modules such as the ones in UNIPS. Open badges were called for by two universities for their simplicity. Besides offering the modules as such, five of the eight universities had included the materials available in UNIPS modules as part of other, more extensive university pedagogy courses.

The benefits of UNIPS for the participating universities were many. The possibility to offer pedagogical training in English and for doctoral students 
were the most commonly mentioned benefits. Additionally, opportunities for diverse (e.g. on specific themes) and flexible (e.g. asynchronous, distance study possibilities) pedagogical studies were appreciated. Finally, the nationwide cooperation was considered fruitful for the quality of the materials and development of developers' own pedagogical expertise.

\subsection{UNIPS students' experiences about studying in UNIPS environment}

UNIPS students' (i.e. university teachers and doctoral students who have participated in UNIPS modules) experiences about studying in UNIPS environment were explored by analyzing data collected with a feedback questionnaire that was sent to all participants after studying some or all of the modules Becoming a teacher, Lecturing and expertise, and How to plan my teaching in autumn 2018 and spring 2019. A total of 81 participants responded to the questionnaire, which is $67 \%$ of all the 121 students who completed at least one of the modules (autumn $2018 \mathrm{~N}=46$, spring $2019 \mathrm{~N}=75$ ). Most of the participants $(70.9 \%)$ reported having experience on online learning as a student and one fifth $(20.9 \%)$ as a teacher. Addressing the crucial need for modernizing university pedagogical courses, almost 90 percent $(88.9 \%)$ of the participants reported that they had not received previously any instruction for teaching online courses. Generally, the participants were satisfied with UNIPS modules and over $90 \%$ of the participants reported that they would recommend the modules to their colleagues. To explore UNIPS students' experiences in more detail, we asked participants to respond to Likert-scale statements concerning their experiences and opinions about the technical (see Figure 4) and pedagogical (see Figure 5) solutions of UNIPS. These Likert-scale statements were not included in the questionnaire in spring 2019 and for that reason the total amount of respondents is lower $(n=43)$ than presented above.

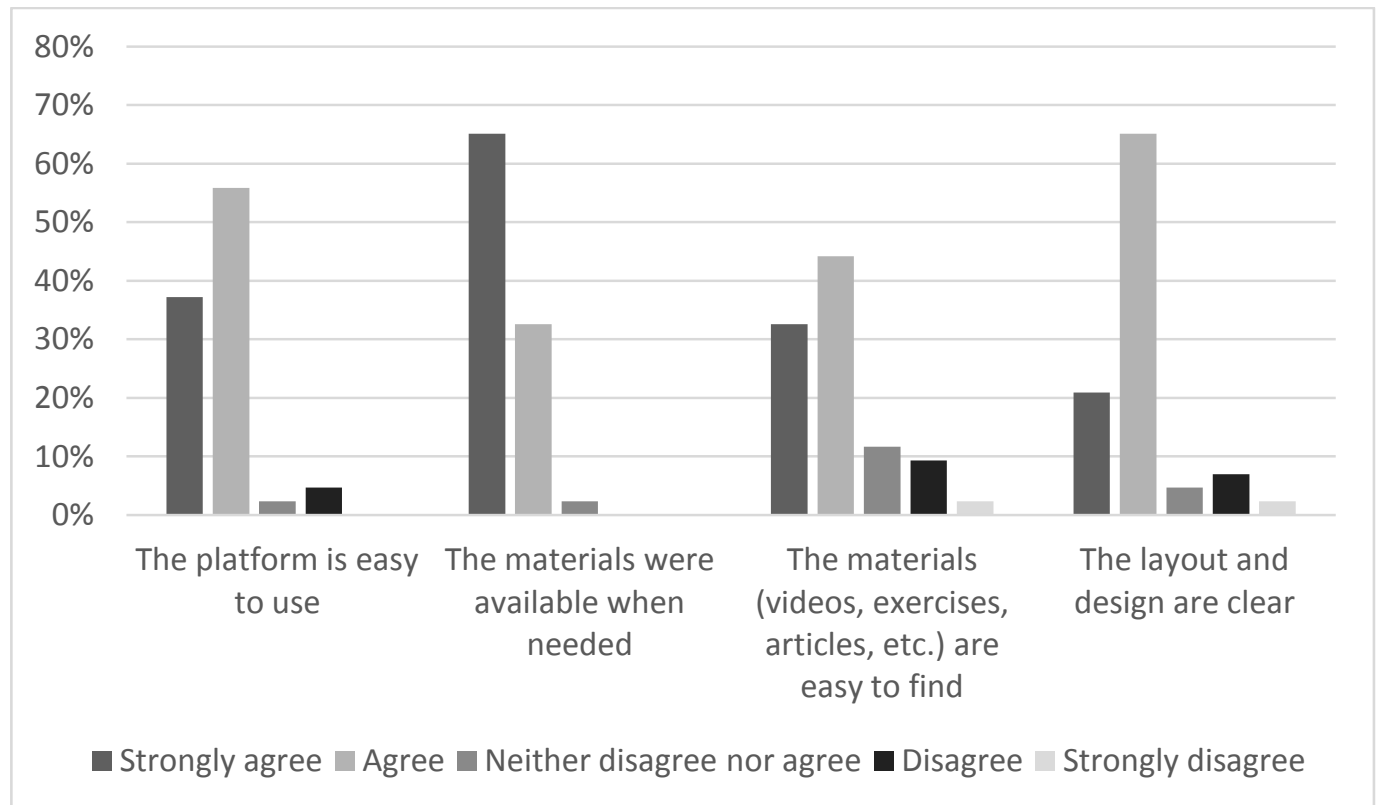

Figure 4: Participants' $(n=43)$ experiences of technical solutions of UNIPS 
An overview of participants' experiences of technical solutions of UNIPS shows that the technical solutions seem to work well. Majority of participants regarded the platform as easy to use $(93.02 \%$ of the participants chose the option "strongly agree" or "agree"), the materials are easy to find $(76.75 \%$ of the participants chose the option "strongly agree" or "agree"), the materials are available when needed (97.68\% of the participants chose the option "strongly agree" or "agree"), and the layout and design are clear $(86.05 \%$ of the participants chose the option "strongly agree" or "agree").

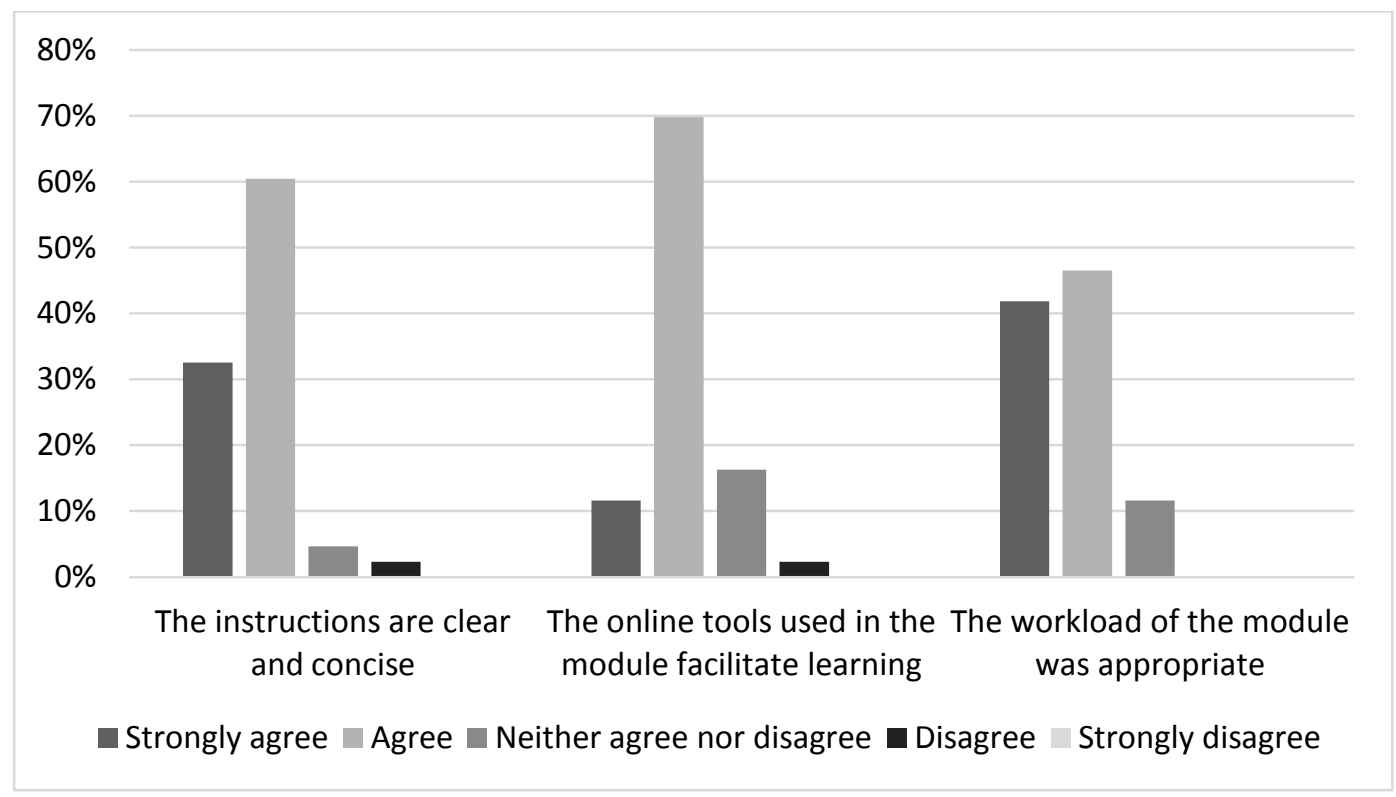

Figure 5: Participants' $(n=43)$ experiences of pedagogical solutions of UNIPS

The analysis of UNIPS students' experiences of the pedagogical solutions of UNIPS shows that also that part seems to work well. Majority of participants considered the instructions to be clear and concise $(93.02 \%$ of the participants chose the option "strongly agree" or "agree"), the online tools used in the module facilitate learning $(81.4 \%$ of the participants chose the option "strongly agree" or "agree"), and the workload of the module was appropriate (88.37\% of the participants chose the option "strongly agree" or "agree").

\subsection{UNIPS students' reasons to take part in the online modules}

To find out why the 81 respondents had decided to participate in studying the UNIPS modules, we asked them to respond to a multiple-choice question about reasons to study online. The amount of options was not limited and many of the participants had chosen several options. The reasons are presented in Figure 6. 


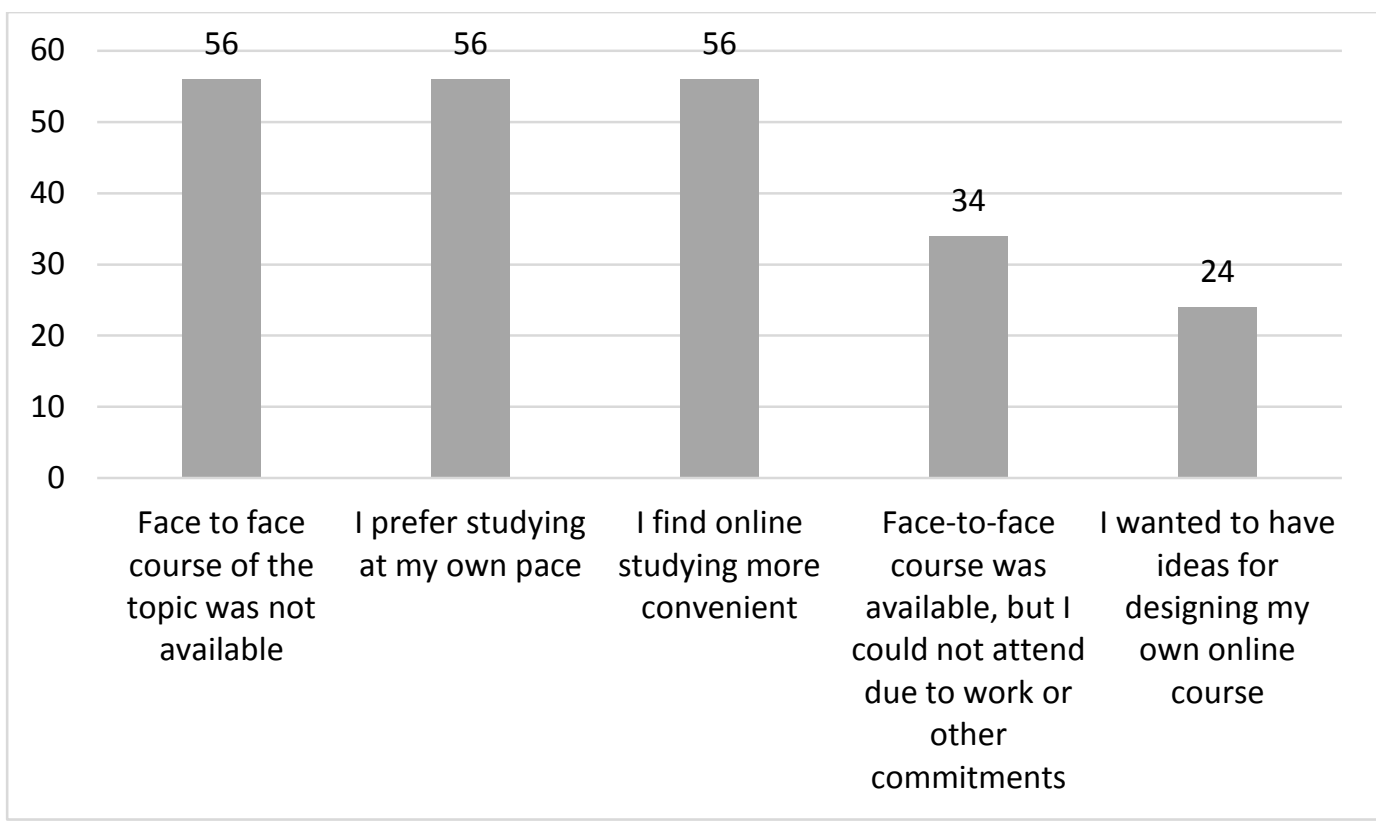

Figure 6: Reasons why respondents $(N=81)$ chose to study the module(s) online. The bars present the number (n) of respondents who have chosen the option.

The three first options about face-to-face course being not available, preferring studying in own pace and finding online studying a convenient form were equally popular. It thus looks like UNIPS has reached also those who would not participate on traditional university pedagogical courses. In addition, when we asked whether the participants had chosen UNIPS because they were not able to participate face-to-face course because of work or other commitments, about forty percent selected that option. UNIPS has also been utilized in modelling online teaching and learning since almost 30 percent reported that they wanted to have ideas for designing their own online courses.

\subsection{UNIPS students' ideas to improve the modules}

To find out how the modules could be improved, we asked the 46 UNIPS students in 2018 to respond to an open-ended question "How would you improve the modules". Students' answers were analyzed by using a data-driven content-analysis and improvement ideas were found in three categories: pedagogical solutions concerning guidance and learning materials, pedagogical solutions concerning social interaction, and technical solutions of the modules. The improvement ideas are presented at Table 2 . 
Table 2: UNIPS students' ideas how to improve the modules

\begin{tabular}{|c|c|c|}
\hline $\begin{array}{l}\text { Pedagogical solutions } \\
\text { concerning guidance and } \\
\text { learning materials } \\
(n=27)\end{array}$ & $\begin{array}{l}\text { Pedagogical solutions } \\
\text { concerning social } \\
\text { interaction } \\
(n=17)\end{array}$ & $\begin{array}{l}\text { Technical solutions } \\
\qquad(n=11)\end{array}$ \\
\hline $\begin{array}{l}\text { - More instructions about } \\
\text { the tasks beforehand } \\
(\mathrm{n}=11) \\
\text { - Upgrading the selection of } \\
\text { the scientific articles }(\mathrm{n}=3) \\
\text { - Breaking the tasks in } \\
\text { smaller parts }(\mathrm{n}=2) \\
\text { - More examples }(\mathrm{n}=1) \\
\text { - Increasing }(\mathrm{n}=5) \text { or } \\
\text { decreasing }(\mathrm{n}=2) \text { the } \\
\text { elements of the modules } \\
\text { - Decreasing the workload } \\
(\mathrm{n}=3)\end{array}$ & $\begin{array}{l}\text { - More interaction with } \\
\text { teachers }(n=3) \text { or other } \\
\text { students }(n=3) \\
\text { - Including face-to-face } \\
\text { teaching }(n=2) \text { or real- } \\
\text { life practice }(n=1) \\
\text { - More feedback }(n=1) \\
\text { - More }(n=2) \text { or less } \\
(n=1) \text { time for tasks or } \\
\text { discussions } \\
\text { - Developing the } \\
\text { discussion part in } \\
\text { general }(n=4)\end{array}$ & $\begin{array}{l}\text { - Direct links to the } \\
\text { articles or other } \\
\text { materials }(\mathrm{n}=4) \\
\text { - Decreasing the technical } \\
\text { elements }(\mathrm{n}=2) \\
\text { - Improving the quality of } \\
\text { videos }(\mathrm{n}=3) \\
\text { - More detailed ideas, like } \\
\text { adding a post folder in } \\
\text { front of the UNIPS page } \\
(\mathrm{n}=1) \text { or a rewind-button } \\
\text { to a certain video }(\mathrm{n}=1)\end{array}$ \\
\hline
\end{tabular}

In line with developers' views, also students thought that more instructions were needed. Considerations for both increasing and decreasing the number of module elements were expressed. Workload was considered too big by only three participants. Social interaction was mentioned by seventeen participants, meaning that there is a need for improvement. Developing the discussion part was mentioned most often. Technical solutions also got some comments, the most usual being adding direct links to articles or other materials.

\section{Discussion}

\subsection{Evaluation of the success of the environment}

The task for this paper was to introduce the goals of the UNIPS platform planned by the developers of eight Finnish universities and to test if these goals have been reached. As the findings presented in this paper address, teachers and doctoral students who have studied the UNIPS modules were generally satisfied with both the technical and pedagogical aspects of the modules. The solution has succeeded in increasing the offering of pedagogical training in English and opportunities for flexible and diverse pedagogical studies nationwide. Targets for development from the developers' viewpoint are more dynamic communication during the planning process and a simpler accreditation of the study credits by issuing open badges, for instance.

Based on the amount of the completed modules during the whole project, UNIPS has succeeded to increase the amount of pedagogical training in Finland. UNIPS has also become rapidly familiar in all Finnish Universities and as the findings of Laato et al. (in press) suggest, UNIPS has managed to increase 1) the diversity of students and 2) the diversity of offered studies in the field of University pedagogy. This means that UNIPS has become a channel for providing pedagogical studies also to non-native speakers and to doctoral students who have not had a chance to participate in pedagogical courses earlier. Research concerning UNIPS modules has also shown that even short 
online pedagogical trainings may have an impact on teachers' pedagogical development, especially when they are not very experienced in teaching (Vilppu et al., 2019).

There were also some challenges when planning, creating, and developing the UNIPS learning solution. In the beginning, some time was spent on finding and choosing the right online platform for the learning environment. The aim was to find a platform that would be safe and easy to access, use, and update. One option was to use the Moodle platform or the intranet of University of Turku. One key question was whether we would aim to create materials only for the staff of our own university, or whether we would move towards "culture of sharing" and try to find a platform that would be easy to share with others in the future. In addition, a modern look and possibility to embed different online tools were important features we were looking for. Finally, a solution was found and WordPress was chosen. It proved to be a good base for the collaborative learning environment of several universities.

Another challenge, especially in the beginning of the project, was to make a pedagogically sound but technically functional and attractive learning solution. All the people in the project had a pedagogical background, but their experience with technology varied. For example, preparing videos were considered challenging in the beginning. The third challenge encountered was also related to technical issues. The possibility to embed different online tools is a challenge because it is not guaranteed how long the tools exist and will be updated by their creator companies. Further, all the universities do not have access to the same research articles, which made finding literature for modules challenging.

A challenge of dropouts was also evident in UNIPS courses. The amount of dropouts in Finnish face-to-face university pedagogy courses is normally very low, often even zero. Thus, compared to face-to-face courses, the amount of dropouts on UNIPS courses was much higher, around 55\% (see in more detail: Laato, et al., 2019). The biggest spike in dropouts is usually in the beginning of the courses (Eriksson et al., 2017), and that was also the case for UNIPS.

\subsection{Limitations}

This study presented the design, implementation, and evaluation of the UNIPS online learning solution for pedagogical studies. Consequently, the study has several limitations. With regard to the chosen pedagogical principles and design, we had to make choices on which principles to follow. For example, although cognitive load theory provides insights into how to design a website, another theory might have yielded different results. In the implementation phase, we had to make decisions about how to follow the selected principles and theories. The chosen web technologies, such as WordPress, also guided the solution to a certain direction whereas another CMS, such as Drupal, could have inspired a different implementation.

The chosen evaluation method consisted of collecting feedback from both the designers and the end users. This was done to ensure a holistic understanding of 
the final solution. However, there are limitations and risks of bias in the way this information was collected and also in participants' perceptions of the platform. The UNIPS feedback survey was distributed to all participants, but only 81 students replied, meaning that many important opinions were never received. Some participants also gave verbal feedback or non-official feedback during guided study periods, which was not included in the current study, but which might have contributed to a more robust understanding of the solution. The designers' perceptions about the platform could also be positively biased as they themselves worked on it and were committed to the project. Lastly, the evaluation of the success of the platform was mostly based on a comparison with previous university pedagogical solutions that were not online courses. To derive the value of these kinds of teacher-driven fully online courses provided by UNIPS, comparison with similar alternatives could be done in the future.

\section{Conclusions and future work}

The UNIPS solution was established from the effort of eight Finnish universities. Each of them were responsible for producing the materials for at least one module, but cooperated also in designing other modules. The guided study option with credit points was locally offered by individual partner universities. However, all content creators offered general guidelines to other universities on how to organize the modules, such as what are the pitfalls to be avoided.

The student feedback on the platform was very positive. Therefore, we can conclude that the open and easily accessible UNIPS materials make a welcome addition to the university pedagogy syllabus. Of course, traditional, face-to-face pedagogy courses are still needed. However, for many staff members and doctoral students the compact UNIPS modules can be the first step towards deepening pedagogical understanding. Curriculum work is needed to be able to embed the modules as a part of other university pedagogical studies. It is also important to promote the new modules in universities. Further, offering discipline-specific modules will remain as a future goal.

This project has shown that this type of an environment is mostly used for guided study. Despite the self-study option, only few students access the website outside the guided study periods (see also Laato et al., 2018). Some ways to support the self-study usage of the modules should be devised. The UNIPS web page could be marketed more strongly as a first aid kit of university pedagogy for first-timers in teaching. The materials could be more visible in different kinds of other web materials and trainings in the future. All in all, we should experiment some solutions to strengthen the individual use of modules, too, and examine whether there are solutions for supporting self-studying or not.

The UNIPS platform has shown to be fairly successful and well-liked medium in offering pedagogical training for university employees and doctoral students. The development of the platform will continue according to the ideas described above. The continuity of the solution after the funding period is guaranteed by the demand for a platform like UNIPS, well prepared basis, and good usability 
of the environment. Some other Finnish universities, and also universities from other countries, that are not participating in the currently funded project have already expressed interest in participating in the UNIPS solution. The solution is hoped to become a common base for all Finnish universities to collaborate in organizing the university pedagogical training. Also, building partnerships with universities from other European countries is one of the future goals of UNIPS.

\section{Acknowledgements and funding}

The study was funded by the Ministry of Education and Culture (Finland), grant number [Grant no. OKM/199/523/2016], grant recipient University of Turku. However, the funding source had no involvement in study design, in the collection, analysis, and interpretation of data, nor writing the report or the decision to submit the article for publication.

We want to thank the next collaborators: University of Turku: Anni Laine, Elizabeth Eta, Erkki Anto, Hanna Nori, Heidi Kettunen, Henna Virtanen, Ilona Södervik, Miia Oinonen, Milla Räisänen, Neea Heinonen, Niko Aaltonen \& Trang Nguyen; Aalto University: Jukka Välimäki \& Virve Pekkarinen; University of Eastern Finland: Antti Kauppila, Krista Sutinen, Tuula Heide \& Ulla Ritvanen; Hanken: Alona Chmilewsky \& Susanna Taimitarha; University of Jyväskylä: Anita Malinen, Juha Lahti \& Kari Toiviainen; LUT University: Katja Lahikainen \& Pirjo Kuru; University of Oulu: Jonna Hurskainen, Katherine Tingzon \& Pekka Mertala; Tampere University: Heta Rintala.

\section{References}

Bailey, C., \& Card, K. (2009). Effective pedagogical practices for online teaching: Perception of experienced instructors. The Internet and Higher Education, 12(3-4), 152-155.

Boettcher, J. V., \& Conrad, R. M. (2016). The Online Teaching Survival Guide. Simple and Practical Pedagogical Tips. San Francisco, CA: Jossey-Bass.

Combéfis, S., Bibal, A., \& Van Roy, P. (2014). Recasting a Traditional Course into a MOOC by Means of a SPOC. Proceedings of the European MOOCs Stakeholders Summit, 205-208.

Eriksson, T., Adawi, T., \& Stöhr, C. (2017). “Time is the bottleneck": a qualitative study exploring why learners drop out of MOOCs. Journal of Computing in Higher Education, 29(1), 133-146.

Feinberg, S., \& Murphy, M. (2000). Applying cognitive load theory to the design of webbased instruction. In Proceedings of IEEE professional communication society international professional communication conference and Proceedings of the 18th annual ACM international conference on Computer documentation: technology \& teamwork (pp. 353-360). IEEE Educational Activities Department.

Hakkarainen, K., Palonen, T., Paavola, S., \& Lehtinen, E. (2004). Communities of networked expertise: Professional and educational perspectives. Amsterdam: Elsevier Science.

Heo, M., \& Chow, A. (2005). The impact of computer augmented online learning and assessment tool. Journal of Educational Technology \& Society, 8(1), 113-125.

Hevner, A. R. (2007). A three cycle view of design science research. Scandinavian Journal of Information Systems, 19(2), 87-92.

Hrastinski, S. (2008). Asynchronous and synchronous e-learning. Educause quarterly, 31(4), 51-55. 
Huang, N. F., Lee, C. A., Huang, Y. W., Ou, P. W., Hsu, H. H., Chen, S. C., \& Tzengßer, J. W. (2017) On the Automatic Construction of Knowledge-Map from Handouts for MOOC Courses. In J.S. Pan, P.W. Tsai, J. Watada, \& L. Jain (Eds.), Advances in Intelligent Information Hiding and Multimedia Signal Processing. IIH-MSP 2017. Smart Innovation, Systems and Technologies (pp. 107-114). Springer, Cham.

Hyland, T. (2019). Vocational studies, lifelong learning and social values: investigating education, training and NVQs under the new deal. London: Routledge.

Khalil, H., \& Ebner, M. (2014). MOOCs completion rates and possible methods to improve retention-A literature review. In Proceedings of World Conference on Educational Multimedia, Hypermedia and Telecommunications 2014 (pp. 1236-1244). Chesapeake, VA: AACE.

Laato, S., Salmento, H., \& Murtonen, M. (2018). Development of an online learning platform for university pedagogical studies - Case study. CSEDU 2018 Proceedings of the 10th International Conference on Computer Supported Education, 2, 481-488. doi:10.5220/0006700804810488

Laato, S., Lipponen, E., Salmento, H., Vilppu, H., \& Murtonen, M. (2019). Minimizing the number of dropouts in university pedagogy online courses. CSEDU 2019 Proceedings of the 11th International Conference on Computer Supported Education, 1, 587-596. doi:10.5220/0007686005870596

Laato, S., Salmento, H., Heinonen, N., Vilppu, H., Lipponen, E., Virtanen, H., \& Murtonen, M. (in press). Solving diversity issues in university staff training with UNIPS pedagogical online courses. Learning with MOOCS 2019.

Mayer, R. E., Moreno, R., Boire, M., \& Vagge, S. (1999). Maximizing constructivist learning from multimedia communications by minimizing cognitive load. Journal of educational psychology, 91(4), 638.

Mikkilä-Erdmann, M., Ahopelto, I., Virtanen, H., Kääpä, P., \& Olkinuora, E. (2012). Conceptual understanding of cardiovascular system among first year medical students. Instructional Science, 40, 745-754.

Murtonen, M., \& Vilppu, H. (under review). Change in university pedagogical culture The impact of increased pedagogical trainings on first teaching experiences.

Oakley, B., Poole, D., \& Nestor, M. (2016). Creating a Sticky MOOC. Online Learning, 20(1), 13-24.

Paas, F., Tuovinen, J. E., Tabbers, H., \& Van Gerven, P. W. (2003). Cognitive load measurement as a means to advance cognitive load theory. Educational psychologist, 38(1), 63-71.

Picciano, A. G. (2017). Theories and frameworks for online education: Seeking an integrated model. Online Learning, 21(3), 166-190. doi:10.24059/olj.v21i3.1225

Richardson, J. C., Maeda, Y., Lv, J., \& Caskurlu, S. (2017). Social presence in relation to students' satisfaction and learning in the online environment: A meta-analysis. Computers in Human Behavior, 71, 402-417.

Simons, M. (2006). 'Education through research' at European universities: Notes on the orientation of academic research. Journal of Philosophy of Education, 40(1), 31-50.

Simons, M., \& Elen, J. (2007). The 'research-teaching nexus' and 'education through research': an exploration of ambivalences. Studies in Higher Education, 32(5), 617631.

Stahl, G., Koschmann, T., \& Suthers, D. (2014). Computer-Supported Collaborative Learning. In R.K. Sawyer (ed.) The Cambridge Handbook of the Learning Sciences (2nd ed., pp. 479-500). New York, NY: Cambridge University Press.

Tracy, J. P., \& Albers, M. J. (2006). Measuring cognitive load to test the usability of web sites. Annual Conference-society for technical communication, 53, 256. 
Tyler-Smith, K. (2006). Early attrition among first time eLearners: A review of factors that contribute to drop-out, withdrawal and non-completion rates of adult learners undertaking eLearning programmes. Journal of Online Learning and Teaching, 2(2), 73-85.

Vilppu, H., Södervik, I., Postareff, L., \& Murtonen, M. (2019). The effect of short online pedagogical training on university teachers' interpretations of teaching-learning situations. Instructional Science, 47(6), 679-709.

\section{Biographies}

\section{Samuli Laato}

Project Researcher and a PhD Student at the Departments of Future Technologies and Education at University of Turku. Currently his research interests include online education and multi-disciplinary learning technologies such as mathematical music composing software and location-based games.

\section{Emilia Lipponen}

M.Soc.Sc., Project Researcher in UNIPS project at the University of Turku during 2018-2019.

\section{Merja Maikkola}

M.Ed. Merja Maikkola is University teacher in University Pedagogics at the University of Oulu, Finland. Partner in UNIPS during 2017 - 2019. She has been developer in university pedagogics since 1995. She has coordinated Peda-forum, a Finnish network for developing instruction and learning in higher education, 20 years.

\section{Mari Murtonen}

Professor of Higher Education Pedagogy, Faculty of Education and Culture, Tampere University, and a Research Leader of the UNIPS solution at the University of Turku during 2017-2019. Her research interests are in higher education learning and teaching, especially in how to foster students' development of scientific thinking and teachers' pedagogical expertise in different environments.

\section{Martti Mäkinen}

Director of Centre for Languages and Business Communication, Hanken School of Economics. PhD, Title of Docent, Associate Professor in English. His research interests are in teaching of communication in higher education, learner academic writing, and corpus linguistics.

\section{Johanna Naukkarinen}

D. Sc. (Tech), post-doctoral researcher and project manager with the School of Energy Systems at Lappeenranta-Lahti University of Technology LUT. Her main research interests relate to technology and society, gender diversity and teaching and learning within engineering education.

\section{Eila Pajarre}


D. Sc. (tech.), Leader of Services for Pedagogical development team in Tampere University. Her research interest covers the field of teaching and learning in higher education and she is currently working in projects about work-integrated pedagogy in higher education, university pedagogical support for teachers, and support for students' wellbeing. She has previously studied also the university teachers' working-life cooperation in teaching and the practices of internships in higher education.

\section{Heidi Salmento}

(M.Ed.) works as a Doctoral Student at Doctoral Programme on Learning, Teaching and Learning Environments Research at the Department of Teacher Education at the University of Turku. She is a developer of the pedagogical and technical solution of UNIPS.fi digital learning environment. Her areas of research include learning and teaching in higher education, the development of university students' scientific thinking and the pedagogical use of educational technology.

\section{Sara Selänne}

B.Ed. Education Specialist, Education and Learning, Tampere University. Also Project Manager in a project concerning the new electronic examination system introduced by Tampere University. Areas of expertise include the development of university teaching and digital pedagogy.

\section{Terhi Skaniakos}

$\mathrm{PhD}$, Senior Specialist, Student and Academic Services, University of Jyväskylä. Skaniakos is an expert in University Pedagogy and her research interests are in teacher development, peer group mentoring and guidance in higher education.

\section{Paula Vaskuri}

M.A. Paula Vaskuri is Head of IT Services for Teaching in IT Services of University of Oulu, Finland. Partner in UNIPS during 2017 - 2019. She has strong expertise in digital pedagogics in university teaching and learning. She has been developer in university pedagogics since 2001 and has wide expertise in academic continuing education also in local, national and international contexts mainly in educational field of science.

\section{Henna Vilppu}

PhD (Education), University Research Fellow at the Unit for University Pedagogy, Department of Teacher Education, University of Turku, Finland. Her research interests are in higher education learning and teaching, especially in regulation of learning, conceptions of teaching and pedagogical development.

\section{Terhi Virkki-Hatakka}

D.Sc. (Tech.), Project manager, School of Business and Management, LUT University, member of the J. Hyneman Center Team, and developing coordinator at LUT Doctoral School. Her current research interests and tasks in national and international projects are related to doctoral education development, and fostering multidiscipline innovations, co-creation and student entrepreneurship. 